\title{
HIDROLISIS SELULOSA MENGGUNAKAN KATALIS KARBON TERSULFONASI BERBASIS CANGKANG KEMIRI
}

\section{CELLULOSE HYDROLYSIS CATALYZED BY SULFONATED CARBON FROM CANDLENUT SHELL}

\author{
Dian Halimah Batubara $^{1}$, Taslim ${ }^{1 *}$, Seri Maulina ${ }^{1}$, Iriany ${ }^{1,2}$ \\ ${ }^{1}$ Departemen Teknik Kimia, Fakultas Teknik, Universitas Sumatera Utara \\ Jl. Almamater kampus USU Medan, 20155, Indonesia \\ ${ }^{2}$ Pusat Unggulan Natural Resources berbasis Teknologi, Univesitas Sumatera Utara \\ Jl. Dr. Mansur No.9, Medan, Indonesia \\ *Email: taslim_hr@yahoo.co.id
}

\begin{abstract}
Abstrak
Alang-alang mengandung selulosa yang dapat dikonversi menjadi glukosa melalui proses hidrolisis menggunakan katalis asam cair anorganik. Penggunaan katalis tersebut dapat menyebabkan masalah korosi, mencemari lingkungan, dan pemisahan produk yang kompleks. Untuk mengatasi masalah tersebut digunakanlah katalis karbon tersufonasi. Penelitian ini bertujuan menguji cangkang kemiri sebagai sumber karbon untuk penyangga katalis yang direaksikan dengan asam sulfat, dan mengaplikasikannya dalam reaksi hidrolisis selulosa. Cangkang kemiri dikarbonisasi pada rentang suhu $300-550^{\circ} \mathrm{C}$ selama 4 jam. Karbon yang terbentuk disulfonasi pada suhu $120-150^{\circ} \mathrm{C}$ selama 6 jam. Karbon tersulfonasi diuji kapasitas $\mathrm{H}^{+} /$tingkat keasamaan. Karbon dengan kapasitas asam tertinggi selanjutnya digunakan sebagai katalis asam padat pada reaksi hidrolisis alang-alang. Glukosa yang diperoleh dianalisis dengan metode dinitrosalicylic acid (DNS). Hasil penelitian ini menunjukkan bahwa karbon tersulfonasi berbasis cangkang kemiri dapat digunakan sebagai katalis heterogen pada reaksi hidrolisis alang-alang.
\end{abstract}

Kata kunci: cangkang kemiri, karbonisasi, sulfonasi, hidrolisis, alang-alang

\begin{abstract}
Cogon grass (Imperata cylindrica) contains cellulose which is convertible to glucose through hydrolysis by using inorganic liquid acid catalyst. However, the use of such catalyst leads to corrosion problem, environment pollution, and complex separation. To overcome this problem, a sulfonated carbon catalyst was proposed. This study aimed to evaluate candlenut shell as carbon source for catalyst support in sulfonated carbon catalyst, and its application in cellulose hydrolysis. Candlenut shell was carbonized at $300-550^{\circ} \mathrm{C}$ for $4 \mathrm{~h}$. Resulting carbon was sulfonated at $120-150^{\circ} \mathrm{C}$ for $6 \mathrm{~h}$. Sulfonated carbon was assessed for its $\mathrm{H}^{+}$capacity/acidity. The carbon with highest acidity was applied as solid acid catalyst in cogon grass hydrolysis. Resulting glucose was analyzed by dinitrosalicylic acid (DNS) method. Results suggest that sulfonated carbon from candlenut shell can be utilized as heterogeneous catalyst in cogon grass hydrolysis.
\end{abstract}

Keywords: candlenut, carbonation, sulfonation, hydrolysis, cogon grass

\section{Pendahuluan}

Alang-alang (Imperata cylindrica) mempunyai potensi besar sebagai sumber energi terbarukan karena mudah diperoleh, tidak bersaing dengan bahan pangan, memiliki daya adaptasi terhadap lingkungan dan cepat tumbuh. Indonesia memiliki luas lahan alang-alang mencapai 10 juta hektar. Komposisi kimia alang-alang terdiri dari 42,5\% selulosa, 29,3\% hemiselulosa dan $17,2 \%$ lignin. Kandungan selulosa yang tinggi ini berpotensi untuk dikonversi menjadi glukosa dengan menggunakan proses hidrolisis dan dapat dijadikan sebagai substrat energi alternatif, untuk memproduksi berbagai bahan kimia industri penting seperti etanol, asam organik, hidrokarbon, dan monomer untuk polimer [12].

Hidrolisis selulosa umumnya menggunakan katalis cair asam anorgaik. Katalis asam cair anorganik ini memiliki kekurangan karena dapat menyebabkan korosi, pemisahan produk sukar dilakukan, dan mencemari lingkungan. Untuk memperbaiki persoalan tersebut, alternatif lain terus diupayakan. Salah satu diantaranya adalah menggunakan katalis heterogen atau katalis asam padat [19]. Katalis heterogen yang dimaksud berupa 
katalis karbon tersulfonasi. Karbon tersulfonasi ini dibuat dengan mereaksikan material karbon dengan asam sulfat. Sumber karbon dapat diperoleh dari berbagai biomassa.

Karbon aktif dari biomassa ini selain murah juga memiliki pori-pori dan luas permukaan yang besar sehingga dapat diaplikasikan pada reaksi hidrolisis selulosa dengan melakukan sedikit modifikasi [19]. Karbon aktif telah digunakan sebagai penyangga katalis pada berapa reaksi seperti sintesis glukosa $[1,19]$, dan sintesis biodiesel [2,15]. Sebagai penyangga katalis, karbon aktif sangat aktif pada reaksi fasa cair dan gas [15]. Karbon aktif memiliki banyak mikro pori sehingga asam atau basa dapat terserap dengan mudah pada permukaan karbon aktif. Kandungan abu yang rendah juga mempercepat laju reaksi [11]. Ikatan pada karbon aktif bersifat inert tanpa mengganggu reaksi. Selain itu, karbon aktif dapat juga digunakan pada reaksi dengan suhu dan tekanan tinggi. Karakteristik karbon aktif tidak berubah pada suhu dan tekanan tinggi [14].

Penggunaan karbon sebagai penyangga katalis dalam hidrolisis selulosa telah dilaporkan dalam beberapa literatur, tetapi terbatas kepada karbon yang berasal cangkang sawit [1], dari pinus [13], rumputrumputan [16], dan ampas tebu [17]. Hingga saat ini, penggunaan karbon aktif dari cangkang kemiri belum pernah dilaporkan. Oleh karena itu, penelitian ini bertujuan menguji cangkang kemiri sebagai sumber karbon untuk penyangga katalis yang disulfonasi dengan asam sulfat, dan mengaplikasikan dalam reaksi hidrolisis alang-alang.

\section{Teori}

Karbon aktif telah digunakan secara luas sebagai adsorben, katalis, dan penyangga katalis karena memiliki luas permukaan yang besar, struktur pori dan gugus fungsi yang melimpah di permukaannya. Kemampuan adsorpsi dan katalitik karbon aktif bergantung pada struktur fisik dan sifat kimia permukaan [8]. Karbon aktif sendiri tidak dapat langsung digunakan sebagai katalis pada hidrolisis selulosa karena memiliki tingkat keasaman yang rendah, sehingga memberikan yield glukosa yang rendah. Perlakuan kimia dengan asam sulfat dapat meningkatkan kemampuan katalitik karbon aktif secara signifikan [1,19].

Material karbon yang digunakan sebagai penyangga katalis harus dalam bentuk struktur poliaromatik hidrokarbon. Untuk membentuk struktur poliaromatik, proses karbonisasi biasanya dilakukan pada suhu $\pm 400^{\circ} \mathrm{C}$. Selanjutnya karbon direaksikan dengan asam sulfat membentuk karbon tersufonasi. Gugus sulfonat yang mengandung $\mathrm{H}^{+}$dapat bertindak sebagai asam $[3,20]$ diharapkan terikat pada struktur aromatiknya $[3,6]$. Gugus inilah yang bertindak sebagai katalis pada reaksi hidrolisis selulosa.

Kelebihan karbon sebagai penyangga katalis karena tahan asam dan basa, temperatur dan tekanan tinggi. Selain itu bersifat inert, mudah didaur ulang dan memiliki luas permukaan yang besar, dan memiliki sifat katalitik yang baik. Pemisahan katalis dari campuran reaksi mudah dilakukan dengan cara filtrasi, dan dapat digunakan kembali, sehingga lebih efisien, dan ekonomis. Banyak substrat/bahan baku yang dapat digunakan dan cocok untuk produksi glukosa melalui proses hidrolisis selulosa $[5,10]$.

\section{Metodologi Penelitian \\ Bahan Baku dan Peralatan}

Bahan baku utama digunakan dalam proses pembuatan karbon tersulfonasi meliputi alang-alang dan cangkang kemiri yang diperoleh dari Kabanjahe, Kabupaten Karo, Sumatera Utara. Sedangkan bahanbahan kimia seperti asam sulfat pekat $\left(\mathrm{H}_{2} \mathrm{SO}_{4}\right)$, barium chloride $\left(\mathrm{BaCl}_{2}\right)$, pereaksi DNS, sodium hidroxide $(\mathrm{NaOH})$, KNa-tartrat, dibeli dari Rudang Jaya, Medan.

Peralatan utama yang digunakan adalah reaktor batch, sedangkan peralatan penunjang seperti muffle furnace, timbangan digital 4 desimal, peralatan kaca seperti beaker glass dan buret. Peralatan analisis yang dibutuhkan adalah spectrometer UV-Vis dan Energy Dispersive Spectroscopy (EDS).

\section{Persiapan Alang-Alang}

Alang-alang diambil dan dipisahkan dari akarnya. Alang-alang dibersihkan dengan air sampai bersih, lalu dipotong dengan pisau hingga berukuran kecil, dan dikeringkan dalam oven pada suhu $105^{\circ} \mathrm{C}$ selama 2 jam. Setelah dingin mencapai suhu kamar alang-alang dihancurkan dengan ball mill dan diayak menggunakan ayakan 50 mesh. Serbuk alang-alang disimpan dalam wadah tertutup.

\section{Pembuatan Katalis}

Pembuatan karbon tersulfonasi mengadopsi prosedur yang dilaporkan oleh Fraga et al [1] dan Ormsby et al [13] dengan melakukan beberapa modifikasi. Cangkang kemiri dibersihkan dari kotoran dan dicuci. Setelah itu cangkang kemiri dipanaskan dalam oven pada suhu $110^{\circ} \mathrm{C}$ selama 2 jam. Proses karbonsiasi dalam furnace pada suhu $300^{\circ} \mathrm{C}$ selama 4 jam sehingga membentuk karbon. Karbon tersebut dihancurkan dan diayak dengan ayakan 50 mesh. Serbuk karbon dipanaskan di dalam oven pada suhu $110^{\circ} \mathrm{C}$ selama 60 menit. Serbuk karbon sebanyak 5 gram diletakkan di dalam beaker glass dan ditambahkan larutan $\mathrm{H}_{2} \mathrm{SO}_{4} 96 \%$ sebanyak $50 \mathrm{ml}$, lalu diaduk selama 15 menit. Setelah itu, dituangkan ke dalam wadah keramik dan ditempatkan di muffle furnace. Kemudian dipanaskan selama 6 jam pada suhu $120^{\circ} \mathrm{C}$. Selanjutnya, karbon yang telah tersulfonasi didinginkan dan dicuci dengan aquades panas $\left(90^{\circ} \mathrm{C}\right)$ sampai tidak ada sulfat yang terdeteksi dengan menggunakan larutan $\mathrm{BaCl}_{2}$. Karbon hasil sulfonasi ini dikeringkan pada suhu $110^{\circ} \mathrm{C}$ selama 24 
jam. Prosedur yang sama diulangi, tetapi dengan variasi suhu karbonisasi $\left(350,450\right.$ dan $\left.550^{\circ} \mathrm{C}\right)$ dan variasi suhu sulfonasi $\left(150\right.$, dan $\left.180^{\circ} \mathrm{C}\right)$.

Karbon tersulfonasi dianalisis dengan uji keasaman dengan metode titrasi. Sedangkan analisis kandungan sampel dilakukan menggunakan EDS. Karbon dengan kapasitas $\mathrm{H}^{+}$tertinggi selanjutnya digunakan untuk proses hidrolisis.

\section{Proses Hidrolisis}

Hidrolisis selulosa menjadi glukosa menggunakan prosedur yang dilaporkan oleh Ormsby et al. [13] dan Li et al. [16] dengan melakukan beberapa modifikasi. Serbuk alang-alang kering ditimbang sebanyak 2,5 gram, dan dimasukkan ke dalam stainless steel batch reactor. Selanjutnya ditambahkan katalis karbon aktif tersulfonasi sebanyak 1 gram, dan air sebanyak $50 \mathrm{ml}$. Pemanasan dilakukan sampai suhu $100{ }^{\circ} \mathrm{C}$, selama 6 jam. Campuran reaksi dikeluarkan dari reaktor dan dilakukan uji glukosa dengan metode DNS [4]

\section{Hasil dan Pembahasan}

\section{Analisis Bahan Baku Alang-Alang}

Analisis alang-alang meliputi kadar selulosa dan kadar air. Hasil analisis kadar selulosa didapat $35,70 \%$ yang mendekati kadar selulosa dari literatur $\pm 40 \%$ [12]. Sedangkan kadar air awal mencapai $74.4 \%$.

\section{Analisis EDS}

Hasil analisis dengan EDS cangkang kemiri, karbon sebelum sulfonasi, dan karbon setelah sulfonasi dirangkum dalam tabel 1. Dari table 1 dapat dilihat bahwa dalam cangkang kemiri, unsur karbon dan oksigen mendominasi dibanding unsur lainnya. Setelah dikarbonisasi, tampak bahwa unsur karbon semakin tinggi sementara unsur lain seperti oksigen dan kalsium menurun. Hal ini disebabkan selama karbonisasi, atom karbon akan menyatu dan membentuk ikatan yang lebih stabil, sementara senyawa lainnya dapat menguap ataupun mengalami pemutusan ikatan [9].

Tabel 1. Kandungan Cangkang Kemiri (CK), Karbon Sebelum Tersulfonasi (KST), dan Karbon Tersulfonasi (KT)

\begin{tabular}{|c|c|c|c|}
\hline Unsur & $\begin{array}{c}\text { CK } \\
(\boldsymbol{\%})\end{array}$ & $\begin{array}{c}\text { KST } \\
(\boldsymbol{\%})\end{array}$ & $\begin{array}{c}\text { KT } \\
(\boldsymbol{\%})\end{array}$ \\
\hline $\mathrm{C}$ & 53,60 & 72,23 & 71,57 \\
\hline $\mathrm{O}$ & 37,87 & 27,77 & 25,21 \\
\hline $\mathrm{Ca}$ & 7,95 & - & 0,63 \\
\hline $\mathrm{Fe}$ & 0,58 & - & - \\
\hline $\mathrm{S}$ & - & - & 2,59 \\
\hline
\end{tabular}

Setelah disulfonasi terjadi penurunan kandungan karbon dan oksigen, sementara itu terdapat unsur $\mathrm{S}$ sebesar $2.59 \%$. Hal ini menguatkan dugaan bahwa gugus sulfonat telah melekat pada pori-pori karbon.

\section{Kapasitas $\mathrm{H}^{+}$atau Nilai Keasaman}

Tabel 2 menunjukkan pengaruh suhu karbonisasi dan suhu sulfonasi terhadap kapasitas $\mathrm{H}^{+}$gugus asam sulfonat $\left(\mathrm{SO}_{3} \mathrm{H}\right)$ katalis. Kapasitas ion $\mathrm{H}^{+}$inilah yang terikat pada gugus sulfonat yang diharapkan berperan sebagai katalis dalam proses hidrolisis. Proses pembuatan katalis karbon cangkang kemiri tersulfonasi dilakukan pada berbagai variasi suhu karbonisasi $\left(300^{\circ} \mathrm{C}-550^{\circ} \mathrm{C}\right)$ dan berbagai variasi suhu sulfonasi $\left(120^{\circ} \mathrm{C}-180^{\circ} \mathrm{C}\right)$.

Tabel 2. Kapasitas $\mathrm{H}^{+}$Gusus Sulfonat Pada Berbagai Suhu Karbonisasi (SK) dan Suhu Sulfonasi (SS)

\begin{tabular}{|c|c|c|}
\hline $\begin{array}{c}\text { SK } \\
\left({ }^{\circ} \mathrm{C}\right)\end{array}$ & $\begin{array}{l}\text { SS } \\
\left({ }^{\circ} \mathrm{C}\right)\end{array}$ & $\begin{array}{c}{\text { Kapasitas } \mathbf{H}^{+}}_{(\mathrm{mmol} / \mathrm{g})} \\
\end{array}$ \\
\hline 300 & \multirow{4}{*}{120} & 4,40 \\
\hline 350 & & 4,50 \\
\hline 450 & & 4,43 \\
\hline 550 & & 4,33 \\
\hline 300 & \multirow{4}{*}{150} & 4,35 \\
\hline 350 & & 4,43 \\
\hline 450 & & 4,38 \\
\hline 550 & & 4,25 \\
\hline 300 & \multirow{4}{*}{180} & 4,38 \\
\hline 350 & & 4,40 \\
\hline 450 & & 4,35 \\
\hline 550 & & 4,28 \\
\hline
\end{tabular}

Dari tabel 2 terlihat bahwa pada suhu sulfonasi yang konstan, kapasitas $\mathrm{H}^{+}$atau nilai keasaman mengalami peningkatan dengan bertambahnya suhu karbonisasi hingga $350^{\circ} \mathrm{C}$ dan mengalami penurunan setelah suhu tersebut. Peningkatan suhu menyebabkan terjadi proses karbonisasi yang lebih baik dan karbon aromatik yang lebih aktif akan terbentuk, yang mana hal ini akan mendukung untuk proses sulfonasi [20]. Suhu karbonisasi yang terlalu tinggi akan memberikan pengaruh yang berlawanan terhadap kapasitas $\mathrm{H}^{+}$ pada katalis [20]. Pada suhu yang sangat tinggi terjadi peningkatan pada ukuran dan susunan lembar aromatik yang menyebabkan sedikit situs yang terakses untuk gugus asam sulfonat. Suhu karbonisasi yang sangat tinggi juga membuat struktur karbon lebih rapat dan mengalami kerusakan sehingga membuat reaktan sulit masuk $[1,18]$. Pada suhu rendah, pembentukan karbon tidak sempurna dan tidak cocok digunakan sebagai penyangga katalis. Hal yang sama juga dilaporkan oleh beberapa peneliti lain $[18,20]$.

Suhu karbonisasi cangkang kemiri pada penelitian ini terbaik pada $350^{\circ} \mathrm{C}$ dengan kapasitas asam $4.5 \mathrm{mmol} / \mathrm{g}$. Suhu optimum karbonasi yang dilaporkan dalam literature berada dalam rentang 
$300-400^{\circ} \mathrm{C}$, tetapi bahan baku dari biomassa yang berbeda yakni cangkang sawit dan ampas tebu sebagai sumber karbon [1,18]. Kondisi suhu karbonisasi optimum sangat bergantung pada biomassa yang digunakan.

Tabel 2 juga menunjukkan pengaruh suhu sulfonasi terhadap kapasitas $\mathrm{H}^{+}$atau nilai keasaman gugus sulfonat pada berbagai suhu karbonisasi. Dari tabel 2 terlihat bahwa kapasitas $\mathrm{H}^{+}$tertinggi dihasilkan pada suhu sulfonasi $120^{\circ} \mathrm{C}$ dengan suhu karbonisasi $350^{\circ} \mathrm{C}$, yaitu sebesar $4,5 \mathrm{mmol} / \mathrm{g}$. Karbon tersulfonasi mengandung gugus sulfonat sebagai situs aktif katalis tersebut [3,21]. Pada suhu karbonisasi yang konstan, kapasitas $\mathrm{H}^{+}$mencapai puncaknya pada suhu sufonasi $120^{\circ} \mathrm{C}$ dan mengalami penurunan setelah suhu tersebut. Hal yang yang sama juga dilaporkan oleh beberapa peneliti lain [20]. Namun setelah mencapai suhu $120^{\circ} \mathrm{C}$, kenaikan suhu sulfonasi menyebabkan adanya penurunan kapasitas $\mathrm{H}^{+}$. Hal ini disebabkan karbon telah mengalami kerusakan akibat terlalu tingginya suhu sulfonasi [20]. Suhu proses sulfonasi terbaik pada penelitian ini adalah $120^{\circ} \mathrm{C}$. Suhu sulfonasi yang sama juga dilaporkan dalam literature [1] dengan menggunakan cangkang kelapa sawit sebagai sumber karbon. Karbon tersulfonasi dengan kapasitas $\mathrm{H}^{+}$tertinggi yaitu sebesar 4,5 mmol/g selanjutnya digunakan sebagai katalis untuk proses hidrolisis.

\section{Hidrolisis}

Proses hidrolisis selulosa dari alang-alang menjadi glukosa dengan katalis karbon tersulfonasi sebagai katalis asam padat (heterogen). Dalam penelitian ini juga digunakan katalis asam sulfat sebagai pembanding.

\section{Analisis glukosa dengan spektrofotometer UV-Vis}

Pengukuran kadar glukosa dilakukan dengan metode DNS dengan Spektrofotometer UV-Vis. Pada penelitian ini diperoleh kadar glukosa hasil hidrolisis dengan menggunakan katalis karbon tersulfonasi sebesar $1.2 \%$. Sementara itu dengan menggunakan katalis $\mathrm{H}_{2} \mathrm{SO}_{4}$ kadar glukosa yang diperoleh mencapai $2.3 \%$ seperti ditunjukkan dalam gambar 1 . Walaupun katalis karbon tersulfonasi terdapat gugus sulfonat yang mengandung gugus $\mathrm{H}+$ yang bisa bertindak sebagai katalis dalam proses hidrolisis untuk memecah selulosa menjadi glukosa, kadar glukosa yang diperoleh masih lebih rendah bila dibandingkan dengan menggunakan katalis asam sulfat. Asam sulfat merupakan asam kuat yang mempunyai kekuatan asam yang lebih besar dan merupakan asam yang paling baik untuk hidrolisis [16]. Data awal hidrolisis alang-alang dengan katalis karbon tersulfonasi berbasis cangkang kemiri masih terbatas untuk suhu $100^{\circ} \mathrm{C}$ dan waktu 6 jam. Sementara dalam literatur, suhu hidrolisis bervariasi dari $100-150^{\circ} \mathrm{C}$ dalam rentang waktu yang digunakan 6-24 jam [7,17].

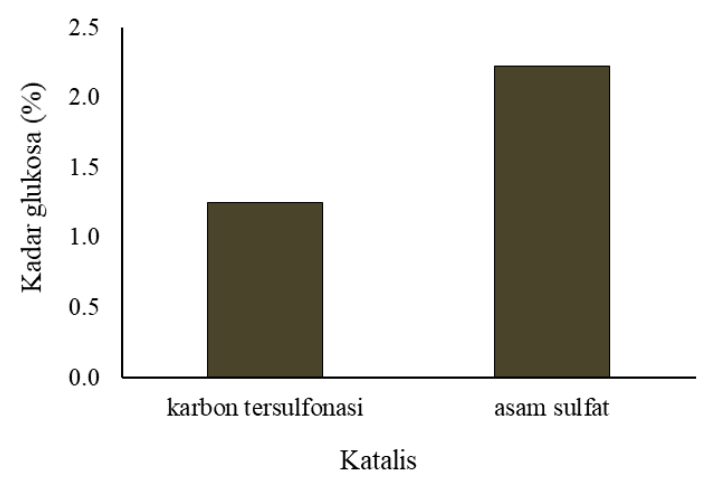

Gambar 1. Kadar glukosa hasil hidrolisis alang-alang pada suhu $100^{\circ} \mathrm{C}$ selama 6 menggunakan dua katalis yang berbeda; karbon tersulfonasi dan asam sulfat

\section{Kesimpulan}

Proses karbonisasi cangkang kemiri untuk menghasilkan karbon, dan selanjutnya direaksikan dengan asam sulfat pekat untuk menghasilkan karbon tersulfonasi. Selama proses tersulfonasi terjadi peningkatan jumlah pori, dan pengikatan gugus sulfonat. Gugus sufonat inilah yang berperan sebagai katalis reaksi hidrolisis. Kondisi terbaik untuk karbonisasi diperoleh pada suhu $350^{\circ} \mathrm{C}$ selama 4 jam, sedangkan untuk proses sulfonasi terbaik diperoleh pada $120^{\circ} \mathrm{C}$ selama 4 jam. Penggunaan 1 gram katalis karbon tersulfonasi untuk menghidrolisis 2,5 gram alang-alang mampu menghasilkan glukosa sebanyak $1.2 \%$.

\section{Ucapan Terima Kasih}

Penulis mengucapkan terima kasih kepada Pengelola Laboratorium Penelitian, Laboratorium Proses Industri Kimia, Departemen Teknik Kimia, Fakultas Teknik, Universitas Sumatera Utara yang telah menyediakan fasilitas selama penelitian ini berlangsung.

\section{Daftar Pustaka}

[1] A.D.C. Fraga, C.P.B. Quitete, V.L. Ximenes, E.F. Sousa-Aguiar, I.M Fonseca, A.M.B. Rego, Biomass derived solid acid as effective hydrolysis catalysts. Journal of Molecular Catalysis A: chemical, 442, (2016) 248-257.

[2] A. Dejean, I.W.K. Ouedraogo, S. Mouras, J. Valette, dan J. Blin, Shea nut shell based catalysts for the production of ethanolic biodiesel, Energy for Sustainable Development, 40 (2017) 103-111. 2017.

[3] A. Onda, Selective hydrolysis of cellulose and polysaccharides into sugar by catalytic hydrothermal method using sulfonated activated carbon. Journal of the Japan Petroleum Institute, 55, (2011) 73-86.

[4] G.L. Miller, Use of dinitrosalicylic acid reagent for determination of reducing sugar, Analytical Chemistry, 31, (1959) 426 - 428.

[5] G.M.G. Maldonado, R.S. Assary, J. Dumesic, 
dan L.A. Curtiss, Experimental and theoretical studies of the acid-catalyzed conversion of furfuryl alcohol to levulinic acid in aqueous solution, Energy Environ. Sci. 5, (2012) 69816989.

[6] I. Mochida, S.H. Yoon, dan W. Qiao, Catalyst in syntheses and carbon precursors. J. Braz. Chem. Soc, 17, (2006) 1059-1073.

[7] J.F. Pang, A.Q. Wang, M.Y. Zheng, dan T. Zhang, Hydrolysis of cellulose into glucose over carbons sulfonated at elevated temperatures, Supplementary Material for Chemical Communication, 46, (2010) 6935-6937.

[8] L. Yang, X.W. Chou, C. Li, X.L. Long, dan W.K. Yuan, Reduction of [Fe(III)EDTA]-catalyzed by activated carbon modified with $\mathrm{KOH}$ solution, Journal of Industrial and Engineering Chemistry, 19, (2013) 784-790.

[9] M. Kwiatkowski, D. Kalderis, dan E. Diamadopoulos, Numerical analysis of the influence of the impregnation ratio on the microporous structure formaton of activated carbon, prepared by chemical activation of waste biomass with phosphoric acid., J. Phys. Chem. Solids, 105, (2017) 81-85.

[10] M. Marzo, A. Gervasini, dan P. Carniti, Hydrolysis of disaccharides over solid acid catalysts under green condition, Carbohydrate Research, 347, (2012) 23-31.

[11] N.S. Pillai, P.S. Kannan, dan S.C. Vettivel, Optimization of transesterification of biodiesel using green catalyst derived from Albizia Lebbeck Pods by mixture design, Renewable Energy, 104, (2017) 185-196.

[12] P. Lanzafame, D.M. Temi, S. Perathoner, A.N. Spadaro, dan G. Centi, Direct conversion of cellulose to glucose and valuable intermediates in mild reaction conditions over solid acid catalysts, Catalysis Today, 179, (2012) 172-184.

[13] R. Ormsby, J.R. Katsner, dan J. Miller, Hemicellulose hydrolysis using solid acid catalysts generated from biochar, Catalysis Today. 190, (2012) 190:89-97.
[14] S. Baroutian, M.K. Aroua, A.A. Abdul Raman, dan N.M. Nik Sulaiman, Potassium hydroxide catalyst supported on palm shell activated carbon for transesterification of palm oil, Fuel Processing Technology, 91, (2010) 1378-1385.

[15]. S.H. Dhawane, T. Kumar, dan G. Halder, Biodiesel synthesis from Hevea brasiliensis oil employing carbon supported heterogeneous catalyst: Optimization by Taguchi Method, Renewable Energy, 89, (2016) 506-514.

[16] S. Li, Z. Gu, dan B.E. Bjornson, A. Muthukumarappan, Biochar based solid acid catalyst hydrolyze biomass. Journal of Environmental Chemical Engineering, 1, (2013) 1174-1181.

[17] W. Namchot, N. Panyacharay, W. Jonglertjunya, dan C. Sakdaronnarong, Hydrolysis of delignified sugarcane bagasse using hydrothermal technique catalyzed by carbonaceous acid catalyst, Fuel, 116, (2014) 608-616.

[18] W.Y. Lou, Q. Guo, W.J. Chen, M.H. Zong, H. Wu, dan T.J. Smith, A highly active bagassederived solid acid catalyst with properties suitable for production of biodiesel, ChemSusChem. 5, (2012) 1-10.

[19] Y.B. Huang, dan Y. Fu, Hydrolysis of cellulose to glucose by solid acid catalysts, Green Chemistry, 15, (2013) 1095-1111.

[20] Y. Zhou, S. Niu, dan J. Li, Activity of the carbon-based heterogeneous acid catalyst from bamboo in esterification of oleic acid with ethanol, Energy Conversion and Management. 114,( 2016) 188-196.

[21] X.C. Zhao, J. Wang, C.M. Chen, Y.Q. Huang, A.Q. Wang, dan T. Zhang, Graphene oxide for cellulose hydrolysis: how it works as a highly active catalyst, Chem. Commun. 50, (2014) 3439-3442. 